\title{
Impact of Intermittent Apnea on Myocardial Tissue Oxygenation-A Study Using Oxygenation-Sensitive Cardiovascular Magnetic Resonance
}

\author{
Dominik P. Guensch ${ }^{1}$, Kady Fischer ${ }^{1,2}$, Jacqueline A. Flewitt ${ }^{1}$, Matthias G. Friedrich ${ }^{1,2 *}$ \\ 1 Stephenson Cardiovascular MR Centre at the Libin Cardiovascular Institute of Alberta, Departments of Cardiac Sciences and Radiology, University of Calgary, Calgary, \\ Alberta, Canada, 2 CMR Research Centre at the Montreal Heart Institute, Université de Montréal, Montreal, Quebec, Canada
}

\begin{abstract}
Background: Carbon dioxide $\left(\mathrm{CO}_{2}\right)$ is a recognized vasodilator of myocardial blood vessels that leads to changes in myocardial oxygenation through the recruitment of the coronary flow reserve. Yet, it is unknown whether changes of carbon dioxide induced by breathing maneuvers can be used to modify coronary blood flow and thus myocardial oxygenation. Oxygenation-sensitive cardiovascular magnetic resonance (CMR) using the blood oxygen level-dependent (BOLD) effect allows for non-invasive monitoring of changes of myocardial tissue oxygenation. We hypothesized that mild hypercapnia induced by long breath-holds leads to changes in myocardial oxygenation that can be detected by oxygenation-sensitive CMR.
\end{abstract}

Methods and Results: In nine anaesthetized and ventilated pigs, 60 s breath-holds were induced. Left ventricular myocardial and blood pool oxygenation changes, as monitored by oxygenation-sensitive CMR using a T2*-weighted steady-state-freeprecession (SSFP) sequence at 1.5T, were compared to changes of blood gas levels obtained immediately prior to and after the breath-hold. Long breath-holds resulted in an increase of $\mathrm{paCO}_{2}$, accompanied by a decrease of $\mathrm{paO}_{2}$ and $\mathrm{pH}$. There was a significant decrease of blood pressure, while heart rate did not change. A decrease in the left ventricular blood pool oxygenation was observed, which was similar to drop in $\mathrm{SaO}_{2}$. Oxygenation in the myocardial tissue however, was maintained throughout the period. Changes in myocardial oxygenation were strongly correlated with the change in paCO during the breath-hold $(r=0.90, p=0.010)$.

Conclusion: Despite a drop in blood oxygen levels, myocardial oxygenation is maintained throughout long breath-holds and is linearly correlated with the parallel increase of arterial $\mathrm{CO}_{2}$, a known coronary vasodilator. Breathing maneuvers in combination with oxygenation-sensitive CMR may be useful as a diagnostic test for coronary artery function.

Citation: Guensch DP, Fischer K, Flewitt JA, Friedrich MG (2013) Impact of Intermittent Apnea on Myocardial Tissue Oxygenation-A Study Using OxygenationSensitive Cardiovascular Magnetic Resonance. PLoS ONE 8(1): e53282. doi:10.1371/journal.pone.0053282

Editor: Wolfgang Rudolf Bauer, University Hospital of Würzburg, Germany

Received October 2, 2012; Accepted November 27, 2012; Published January 3, 2013

Copyright: ( $) 2013$ Guensch et al. This is an open-access article distributed under the terms of the Creative Commons Attribution License, which permits unrestricted use, distribution, and reproduction in any medium, provided the original author and source are credited.

Funding: The Husky Energy Inc., as part of the Husky Energy Program for the Early Detection of Cardiovascular Disease, sponsored this investigation, yet did not have a role in study design, data collection and analysis, decision to publish, or preparation of the manuscript.

Competing Interests: Matthias G. Friedrich is advisor and shareholder of Circle Cardiovascular Imaging Inc., Calgary, AB, Canada. There is a pending patent (US Patent Pending 61680,981 ), which protects the use of breathing maneuvers to induce changes of myocardial oxygenation for diagnostic purposes. This does not alter the authors' adherence to all the PLOS ONE policies on sharing data and materials.

*E-mail: mgwfriedrich@gmail.com

\section{Introduction}

Carbon dioxide $\left(\mathrm{CO}_{2}\right)$ is a potent vasodilator in the cerebrovascular system $[1,2]$. With perturbations as little as such caused by breath holding can induce changes in cerebral blood flow. Recent data from our group indicate that this is paralleled by an increase in myocardial blood flow [3,4]. However, there is little information on the utility of $\mathrm{CO}_{2}$ as a vasodilator for diagnostic testing.

Oxygenation-sensitive CMR detects changes of haemoglobin oxygenation by making use of the fact that its magnetic properties change when transitioning from oxygenated to deoxygenated status: While oxygenated haemoglobin (oxyHb) is diamagnetic exhibiting a weak stabilization of the magnetic field surrounding the molecule, deoxygenated haemoglobin (de-oxyHb) is paramagnetic, de-stabilizing the surrounding field and thereby leading to a loss of magnetic field homogeneity. T2* weighted CMR protocols sensitive to this "blood oxygen level-dependent (BOLD) effect" may show a regional signal intensity (SI) drop of tissue with such a relative increase of de-oxyHb $[5,6]$ or a shortening in $\mathrm{T} 2 *$ time, as seen in myocardial ischemia [7]. Vice versa, increasing blood flow without a matching increase of oxygen consumption leads to a decrease in de-oxyHb and thus to an increased SI. Ogawa et al. used this to detect small variations of regional blood flow due to activation of brain areas in functional magnetic resonance imaging (fMRI) of the brain [8]. Using adenosine-induced coronary vasodilation, we could recently show that the vasodilatory effect leads to a measurable SI increase, which was linearly related to coronary sinus blood oxygenation yet not to blood flow [9].

We hypothesized that long-breath-hold induced hypercapnia leads to changes of myocardial haemoglobin oxygenation, which can be detected by oxygenation-sensitive CMR 


\section{Materials and Methods}

\section{Experimental Protocol}

Nine juvenile male pigs $(24.3 \pm 0.2 \mathrm{~kg})$ were pre-medicated with $600 \mathrm{mg}$ Ketamine, $10 \mathrm{mg}$ Midazolam and $2 \mathrm{mg}$ Fentanyl i.m., then anaesthetized with $20-25 \mathrm{mg} / \mathrm{kg}$ Thiopental to establish an appropriate anaesthesia depth. They were intubated with a standard cuffed endotracheal tube (ID 5.5-6 mm) and ventilated with a Harvard Ventilator. Anaesthesia was maintained with an intravenous drip (1-3 mg/h Midazolam, 1.6-4.8 mg/h Fentanyl) and a nitrous oxide/Isoflurane $(0.6-1.5 \%)$ gas narcosis. To prevent arrhythmia, the animals received a continuous Lidocaine infusion $(1 \mathrm{mg} / \mathrm{min})$. The right carotid artery and the femoral artery were cannulated for invasive blood pressure and arterial blood gas measurements throughout the experiment. The left jugular and femoral vein were cannulated for intravenous infusions. Monitoring of anaesthesia and haemodynamics included $\mathrm{EtCO}_{2}, \mathrm{FiO}_{2} / \mathrm{FiN}_{2} \mathrm{O}$, 3-lead ECG, invasive blood pressure and arterial blood gases. After preparation, the animals were transferred to a clinical 1.5T MRI system (Avanto ${ }^{\circledR}$, Siemens Healthcare, Erlangen, Germany). Custom $12 \mathrm{~m}$ long ventilator tubing connected the ventilator from outside the MR suite. Blood gases were adjusted to a target $\mathrm{paO}_{2}$ of $100 \mathrm{mmHg}$ and a $\mathrm{paCO}_{2}$ of $40 \mathrm{mmHg}$. Then, BOLD-sensitive steady-state-free-precession (SSFP) cine images were acquired in mid left-ventricular short axis views (slice thickness $10 \mathrm{~mm}$, TE $2.78 \mathrm{~ms}$, TR $5.56 \mathrm{~ms}$, flip angle $90^{\circ}$, FOV $280 \times 157.5$, matrix $\left.128 \times 72\right)[9,10]$. Each cine was composed of 20 phases covering the entire cardiac cycle, obtained by retrospective ECG gating. BOLD-SSFP cines were acquired during a $1 \mathrm{~min}$ breath-hold. Immediately after resuming ventilation an arterial blood sample was taken to determine the changes in blood gas levels over the one minute breath-hold. Blood gases were utilized to calculate the approximate arterial haemoglobin saturation using a dissociation curve tool [11] based on the equations of Kelman and Severinghaus [12,13].

\section{Image Analysis}

The images were analyzed with certified software for CMR image analysis $\left(\mathrm{cmr}^{42}\right.$, Circle Cardiovascular Imaging Inc., Calgary, AB, Canada). Image quality was graded prior to SI measurement using visual assessment based on a 1-4 scale: $1=$ good image quality, $2=$ mildly impaired image quality resulting in $<10 \%$ of the total myocardial area excluded, $3=$ limited image quality resulting in $>10 \%$ of the myocardium excluded, $4=\mathrm{a}$ severely non-analyzable image. The mean myocardial SI in the BOLD-sensitive images was automatically calculated after manual tracing of endocardial and epicardial contours in all images of each cine series. Additionally, a region of interest was defined in the centre of the left ventricular (LV) lumen for assessing SI changes in the arterial blood during the breathhold. For the entire cardiac cycle, the area under the curve (AUC) was calculated from the signal intensity of all 20 phases (Figure 1) and expressed as percent change SI between baseline and the end of the breath-hold.

\section{Statistical Analysis}

To determine the SI changes resulting from apnea, the AUC of the first two image sequences were compared to those of the last two images of the breath-hold using a paired t-test. Differences in blood gases and cardiovascular parameters over the breath-hold were analyzed with a paired t-test as well. Pearson's correlation was performed to determine if there were relationships between the \%-change SI and changes in blood gases, heart rate and blood pressure. Values are expressed as mean \pm SEM. Statistical analysis was calculated with GraphPad Prism (GraphPad Software, San Diego, CA) and deemed significant if $p<0.05$.

\section{Ethics Statement}

This study was conducted in accordance with the "Guide to the Care and Use of Experimental Animals" by the Canadian Council on Animal Care. It was approved by the local "Animal Care and Use Board" and the institutional ethics committee.

\section{Results}

One pig was excluded due to a pre-existing severe myocardial wall motion abnormality at baseline. Two pigs died in a sudden cardiac arrest during the preparation of the blood vessels, leaving 6 pigs for the data analysis. Overall, BOLD image quality was good in this study as visual assessment yielded a mean score of $1.3 \pm 0.3$. One pig had $10 \%-15 \%$ of the myocardium excluded in the anterolateral and inferolateral segments due to susceptibility artifacts and two other pigs had $<10 \%$ exclusions in the inferoseptal, inferior and inferolateral segments.

\section{Blood Gases and Cardiovascular Parameters}

The $\mathrm{paCO}_{2}$ significantly increased from $41 \pm 0.4$ to $47 \pm 1 \mathrm{mmHg}$ during apnea $(p<0.001)$ accompanied by a significant decrease in $\mathrm{pH}$ from $7.40 \pm 0.02$ to $7.35 \pm 0.01(p=0.009)$ as shown in Table 1. Also, there was a significant decrease in $\mathrm{paO}_{2}$ from $100 \pm 2$ to $65 \pm 5 \mathrm{mmHg}(p=0.003)$. As a result of the changing $\mathrm{paO}_{2}, \mathrm{paCO}_{2}$ and $\mathrm{pH}$ levels, the calculated $\mathrm{SaO}_{2}$ dropped by $9.9 \pm 3.5 \%(p=0.037)$. There was no change in heart rate but all animals, however, showed a significant drop in blood pressures $(p<0.05)$.

\section{CMR Results}

Between 6 and 8 BOLD SSFP cine series were acquired during the apneic periods. During apnea, there was a strong, yet nonsignificant trend for an increase of myocardial SI $(4.8 \pm 2.2 \%$; $p=0.077$; Figure 2). The increase in myocardial SI was linearly correlated with the change in $\mathrm{paCO}_{2}(\mathrm{r}=0.90, p=0.010$; Figure 3$)$, while there was no correlation between myocardial SI changes and changes of $\mathrm{paO}_{2}$. SI in the LV blood pool decreased during apnea by $8.0 \pm 3.0 \% \quad(p=0.047)$. The relative drop in blood pool SI detected by oxygenation-sensitive $\mathrm{MR}$ was similar to the $9.9 \pm 3.5 \%(p=0.037)$ drop in calculated $\mathrm{SaO}_{2}$. Heart rate was not correlated with changes in SI.

\section{Discussion}

The data indicate that long breath-holds lead to a consistent, transient decrease of the myocardial deoxyhaemoglobin fraction, which can be detected by oxygenation-sensitive imaging. SI changes in oxygenation-sensitive images have to be evaluated in the context of tissue blood flow, vascular homogeneity, and systemic $\mathrm{Hb}$ oxygenation. Our endpoints however refer to repeated measurements and thus are not sensitive to stable systematic confounders. Most importantly, all experiments have been performed under steady conditions with respect to oxygen consumption. The observed changes therefore reflect the tissue response to the increased $\mathrm{CO}_{2}$ caused by the breath-hold.

\section{CMR of Myocardial Oxygen}

Under dynamic conditions, various factors determine myocardial tissue oxygenation. While during constant blood flow (and thus constant $\mathrm{O}_{2}$ supply), an increased $\mathrm{O}_{2}$ demand would result in de-oxygenation and thus a SI decrease, a decreased $\mathrm{O}_{2}$ demand 
A

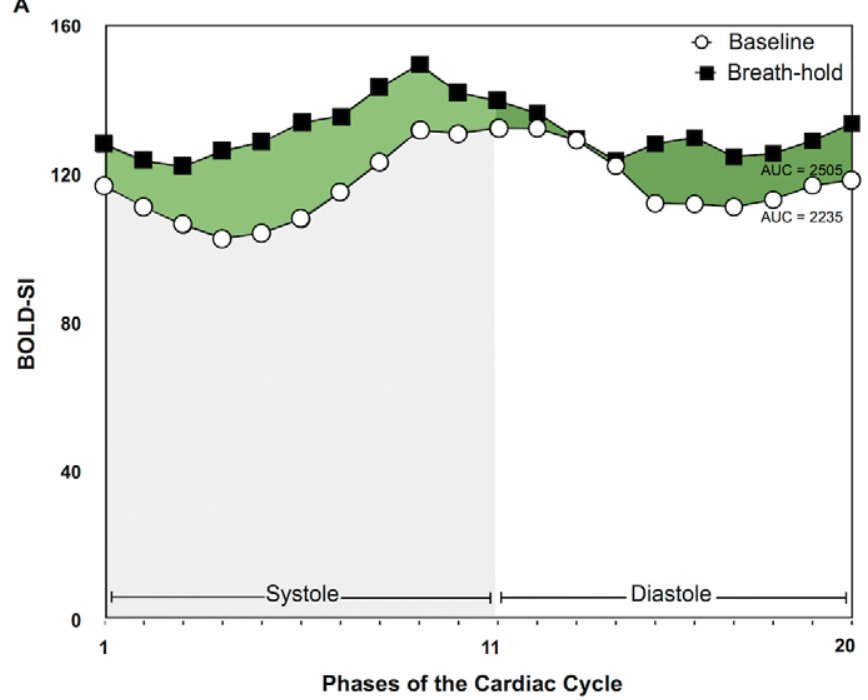

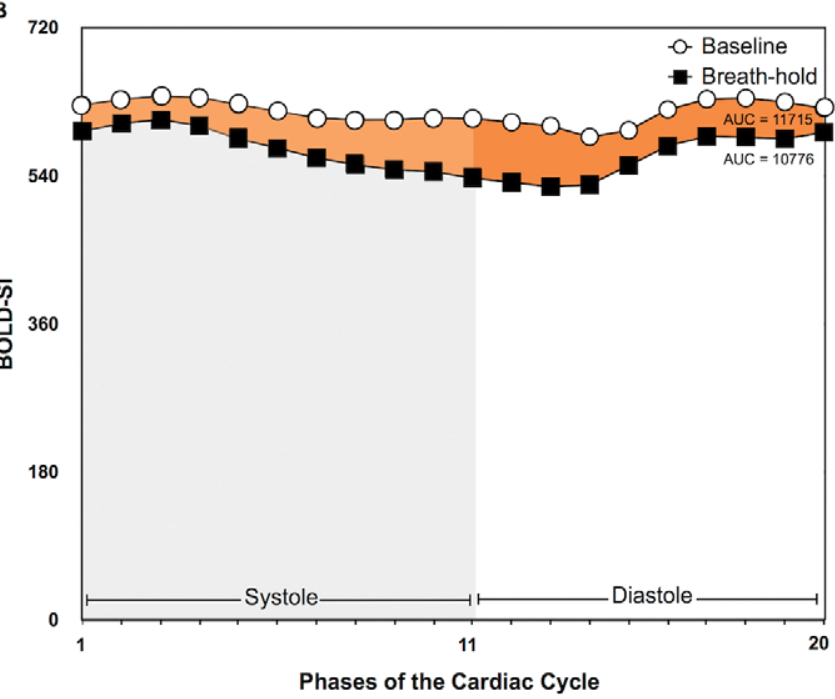

Figure 1. Myocardial and blood pool SI throughout the cardiac cycle. The area under the curve was calculated from the absolute BOLD-SI values of the 20 phases of the cardiac cycle from images obtained at the start and at the end of a breath-hold of both the myocardium (A) and blood pool (B) of one subject.

doi:10.1371/journal.pone.0053282.g001

would have an opposite effect. In the setting of constant $\mathrm{O}_{2}$ demand, an increase of blood flow leads to a decreased fraction of de-oxyHb, exhibiting the BOLD effect used for oxygenationsensitive CMR imaging.

The observed BOLD-effect is predominantly due to changes of inhomogeneities in the magnetic field occurring in and around the myocardial capillaries [14]. Approximately $90 \%$ of the intramyocardial blood volume and thus haemoglobin resides in these vessels [15]. Under resting conditions only a fraction of the capillaries in the myocardium are believed to be perfused. In the presence of a vasodilator without an increase in myocardial oxygen-consumption in healthy myocardium, the opening of arterioles [16] increases the total oxygen supply without a matching change of the demand and thereby reduces the deoxyHb content in the capillary beds. Accordingly, this leads to an increase of $\mathrm{T} 2 *$ of the tissue in the affected perfusion bed $[6,17]$.

Table 1. Blood gas, blood pressure and heart rate analysis.

\begin{tabular}{|c|c|c|c|}
\hline & \multirow{2}{*}{$\begin{array}{l}\text { Baseline } \\
(n=6)\end{array}$} & \multirow{2}{*}{$\begin{array}{l}\begin{array}{l}\text { After } \\
\text { Apnea }\end{array} \\
(n=6)\end{array}$} & \multirow[t]{2}{*}{$p$ Value } \\
\hline & & & \\
\hline \multicolumn{4}{|c|}{ Arterial blood gases [mmHg] } \\
\hline $\mathrm{paCO}_{2}$ & $41 \pm 0.4$ & $47 \pm 1$ & $<0.001$ \\
\hline $\mathrm{paO}_{2}$ & $100 \pm 2$ & $65 \pm 5$ & 0.003 \\
\hline pH & $7.40 \pm 0.02$ & $7.35 \pm 0.01$ & 0.009 \\
\hline \multicolumn{4}{|c|}{ Arterial blood pressures [mmHg] } \\
\hline Systolic & $100 \pm 11$ & $85 \pm 18$ & 0.013 \\
\hline Mean & $74 \pm 9$ & $64 \pm 13$ & 0.035 \\
\hline Diastolic & $59 \pm 9$ & $50 \pm 11$ & 0.029 \\
\hline Heart rate [beats/min] & $110 \pm 14$ & $114 \pm 14$ & 0.448 \\
\hline
\end{tabular}

Mean $( \pm$ SEM) arterial partial pressures $(\mathrm{mmHg})$ of blood gases, invasive blood pressures from the femoral artery and heart rate $(n=6)$.

doi:10.1371/journal.pone.0053282.t001
Several BOLD-sensitive approaches have been used in experimental settings to assess myocardial oxygenation as a marker for coronary artery disease, often using adenosine or dipyridamole as a vasodilator. While healthy vessels dilate and lead to an increase in myocardial SI [7], myocardium subtended by stenotic vessels may show a blunted response to the vasodilatory trigger or even a decrease in myocardial BOLD-SI as supported by a similar study in an experimental model [18]. Recently, Manka et al. reported shortening of $\mathrm{T} 2 *$ times during adenosine infusion in segments subtended by stenotic coronary arteries at 3T [19].

Importantly, SI changes in BOLD-sensitive images acquired during steady conditions have been shown to exclusively reflect changes of $\mathrm{Hb}$ oxygenation $[9,20]$. Of note, such changes are linearly correlated with oxygenation of coronary sinus blood. While an ultimate proof of changes of oxygenation on a tissue level would appear helpful, the required methodology, i.e. invasive procedures in the tissue would interfere with the molecular response and thus become a very strong confounder itself. Previous canine studies at $1.5 \mathrm{~T}$ have found good correlations between BOLD SI increases and the increases of microsphere-measured flow during adenosine indicating that regional changes in BOLD SI were directly related to the relative change in blood flow $[18,21]$. This could be reproduced during adenosine mediated vasodilation at $3 \mathrm{~T}$ in patients with coronary artery disease, where moderate but significant correlations were observed between the BOLD SI change and both, regional myocardial blood flow and coronary flow reserve measurements determined by positron emission tomography with oxygen 15-labeled water [22]. Li et al. compared the SI response to vasodilation with and without increased cardiac workload and could show that SI changes in BOLD CMR images reflect primarily oxygenation and not blood flow [23]. More recently however, Arnold et al. demonstrated that an increase in myocardial blood flow is also correlated to changes in BOLD-SI, until oxygenation reaches a plateau. At this plateau oxygenation is maximal and cannot be increased with further increase of blood flow [24]. Therefore, there is solid evidence that change in blood flow has a secondary effect on SI in oxygenation- 


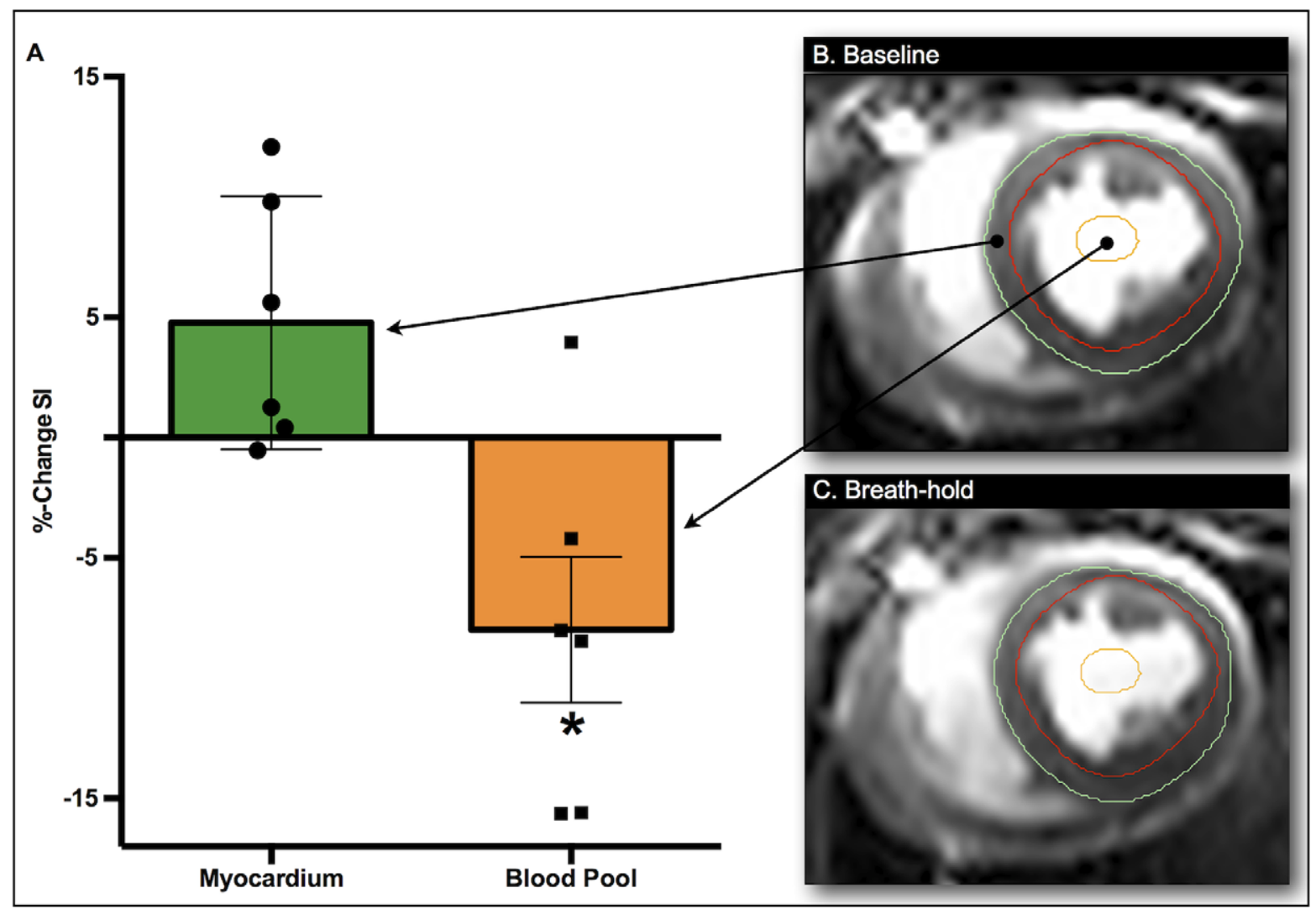

Figure 2. Change in arterial blood pool and myocardial tissue oxygenation during a 60 seconds breath-hold. Phase 11 of the cardiac cycle representing end-systole is presented for both the image from baseline (B) and the end of the breath-hold (C). The analyzed myocardial region is outlined on the BOLD-CMR image by the endocardial (red) and epicardial (green) contours resulting in a trend toward a mean SI increase (+4.8\%; $p=0.077, \mathrm{n}=6)(\mathbf{A})$. The orange contour depicts a region of interest in the blood pool, with a significant mean $\mathrm{SI}$ decrease $(-8.0 \% ; p=0.047)$. doi:10.1371/journal.pone.0053282.g002

sensitive CMR images only, which is simply due to the associated impact on oxygen supply.

\section{$\mathrm{CO}_{2}$ as a Coronary Vasodilator}

To respond to changes in myocardial oxygen consumption, coronary blood flow is tightly controlled using several metabolic

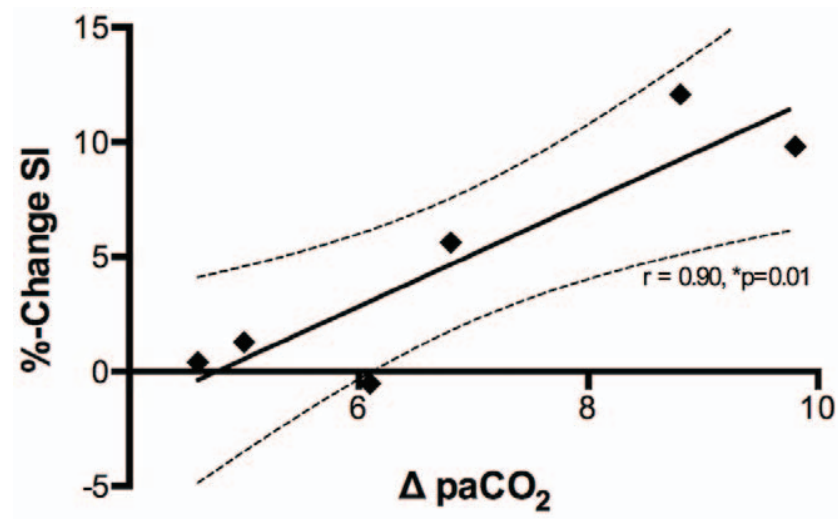

Figure 3. Correlation of myocardial $\mathrm{SI}$ in oxygenation-sensitive CMR images to changes in $\mathbf{p a C O}_{\mathbf{2}}$. Differences in $\mathrm{paCO}_{2}(\mathrm{mmHg})$ are plotted against the \% change in myocardial $S I(n=6)$. The data shows excellent linear correlation $(r=0.90, p=0.010)$. The dashed lines represent the $95 \%$ confidence interval. doi:10.1371/journal.pone.0053282.g003 mechanisms to maintain adequate tissue oxygenation. $\mathrm{CO}_{2}$, a major byproduct of all energy-dependent processes, plays a strong role in this regulation [25], tightly coupling demand and supply by its vasodilatory effect on local blood circulation $[4,26]$. The vasodilatory effect of $\mathrm{CO}_{2}$ and its impact on blood flow [3] and volume [17] have been demonstrated. Changes in systemic $\mathrm{paCO}_{2}$ through breathing maneuvers therefore mimic the effect of vasodilators such as adenosine and dipyridamole.

Our observation that there is a trend toward increased myocardial SI despite a parallel SI drop in arterial blood suggests, that the $\mathrm{CO}_{2}$-mediated increase in vessel diameter and thus perfusion can fully compensate for the drop in arterial haemoglobin saturation during a 60s breath-hold in swine.

Short breath-holds in humans were sufficient to demonstrate increases in cerebral BOLD-sensitive SI in the brain [27]. However, results in animal models were inconsistent [28]. In a rat model of Kannurpatti et al. a drop in SI intensity was observed during a 20 second breath-hold when the animals were ventilated with room air. Increasing the $\mathrm{FiO}_{2}$ to $100 \%$ resulted in increased $\mathrm{SI}$ in BOLD-sensitive images. Of note, there was a larger increase in cerebral blood flow when these changes were induced at a baseline with room air, corresponding with lower $\mathrm{paO}_{2}$ levels. A model of hypercapnia, hypocapnia and hyperoxaemia in anaesthetized dogs, however, showed rather inhomogenous results for different regions of the brain [29]. Through the inhalation of different gas mixtures, BOLD signal intensity in the human brain increased during hypercapnia, yet a larger increase was observed during hypercapnic hyperoxia [30]. 
In contrast to previous studies, which used rather extreme hypercapnic states to elicit changes in coronary blood flow in invasive studies [31-33], we found small increases of $\mathrm{paCO}_{2}$ to be sufficient to exhibit increases of SI. The $\mathrm{CO}_{2}$-dependent coronary flow increase led to an excess oxygen supply which, given the unchanged oxygen demand, expectedly resulted in a lower deoxyHb fraction and thus increased SI in the oxygenation-sensitive images.

During long breath-holds, increases in SI attributed to blood flow may be counteracted by a decrease caused by blood $\mathrm{Hb}$ desaturation. As expected from those physiological considerations, we observed a decrease of the SI of blood reflecting decreased blood oxygenation during prolonged breath-holds. A drop of arterial blood SI likely blunted the effect of the blood flow increase on myocardial oxygenation. Of note, other studies report an additive effect of hypoxia to hypercapnic increases of myocardial blood flow [31-34]. To further understand the competing effects of a breath-hold and the resulting $\mathrm{CO}_{2}$ increase on myocardial tissue oxygenation, it would have been interesting to separate both Hb-desaturation and hypercapnia in this pilot study. We were however also interested in applying a model which would be used as a diagnostic approach in patients. Our results may in fact indicate a diagnostic utility for assessing coronary artery function without the need for the systemic or intracoronary application of pharmacologic vasodilators, which often is associated with side effects. Yet, the clinical feasibility and utility of this approach in spontaneously breathing volunteers/patients and the ability of $\mathrm{CO}_{2}$ as a direct coronary vasodilator to distinguish diseased from healthy vessels such as adenosine requires further investigation.

\section{References}

1. Ainslie PN, Poulin MJ (2004) Ventilatory, cerebrovascular, and cardiovascular interactions in acute hypoxia: regulation by carbon dioxide. J Appl Physiol 97: 149-159. doi:10.1152/japplphysiol.01385.2003.

2. Kety SS, Schmidt CF (1948) The effects of altered arterial tensions of carbon dioxide and oxygen on cerebral blood flow and cerebral oxygen consumption of normal young men. J Clin Invest 27: 484-492.

3. Beaudin AE, Brugniaux JV, Vohringer M, Flewitt J, Green JD, et al. (2011) Cerebral and myocardial blood flow responses to hypercapnia and hypoxia in humans. Am J Physiol Heart Circ Physiol. Available: http://www.ncbi.nlm.nih. gov/pubmed/21724871. Accessed 27 September 2011.

4. Case RB, Greenberg H (1976) The response of canine coronary vascular resistance to local alterations in coronary arterial P CO2. Circ Res 39: 558-566. doi:10.1161/01.RES.39.4.558.

5. Bauer WR, Nadler W, Bock M, Schad LR, Wacker C, et al. (1999) The relationship between the BOLD-induced $\mathrm{T}(2)$ and $\mathrm{T}(2)\left({ }^{*}\right)$ : a theoretical approach for the vasculature of myocardium. Magn Reson Med 42: 1004-1010.

6. Wacker CM, Bock M, Hartlep AW, Beck G, van Kaick G, et al. (1999) AIDMRM6>3.0.CO;2-9.

7. Friedrich MG, Niendorf T, Schulz-Menger J, Gross CM, Dietz R (2003) Blood oxygen level-dependent magnetic resonance imaging in patients with stressinduced angina. Circulation 108: 2219-2223. doi:10.1161/ 01.CIR.0000095271.08248.EA

8. Ogawa S, Lee TM, Kay AR, Tank DW (1990) Brain magnetic resonance imaging with contrast dependent on blood oxygenation. Proc Natl Acad Sci USA 87: 9868-9872.

9. Vöhringer M, Flewitt JA, Green JD, Dharmakumar R, Wang J Jr, et al. (2010) Oxygenation-sensitive CMR for assessing vasodilator-induced changes of myocardial oxygenation. J Cardiovasc Magn Reson 12: 20. doi:10.1186/1532429X-12-20.

10. Dharmakumar R, Qi X, Hong J, Wright GA (2006) Detecting microcirculatory changes in blood oxygen state with steady-state free precession imaging. Magn Reson Med 55: 1372-1380. doi:10.1002/mrm.20911.

11. Varjavand N (2000) Oxyhemoglobin Dissociation Curve. Available: http:// www.ventworld.com/resources/oxydisso/dissoc.html. Accessed 2012 Aug 7.

12. Severinghaus JW (1979) Simple, accurate equations for human blood $\mathrm{O}_{2}$ dissociation computations. J Appl Physiol 46: 599-602.

13. Kelman GR (1966) Digital computer subroutine for the conversion of oxygen tension into saturation. J Appl Physiol 21: 1375-1376.

14. Bauer WR, Nadler W, Bock M, Schad LR, Wacker C, et al. (1999) Theory of coherent and incoherent nuclear spin dephasing in the heart. Phys Rev Lett 83: 4215-4218. doi:10.1103/PhysRevLett.83.4215.
We encountered a decrease of blood pressure, which may have confounded our results by decreasing myocardial workload and we cannot exclude that this was in part due to or modified by cardiosuppressive effects of the anaesthesia. Changes in myocardial SI and blood pressure, however, were not correlated. Thus a significant confounding effect is highly unlikely.

Finally, our model may also be limited by the application of general anaesthesia, since several anaesthetic drugs are known to affect the vascular tone. However, the concept of balanced anaesthesia has likely reduced cardiovascular side effects.

\section{Conclusion}

Despite a drop in blood oxygen levels, myocardial oxygenation is maintained throughout long breath-holds and is linearly correlated with the parallel increase of arterial $\mathrm{CO}_{2}$, a known coronary vasodilator. Breathing maneuvers in combination with oxygenation-sensitive CMR may be useful as a diagnostic test for coronary artery function.

\section{Acknowledgments}

We are indebted to the team of the John V. Tyberg lab, of the University of Calgary, Faculty of Medicine, especially Cheryl Meek, Steven Burgoyne and Kristen Handkamer for animal preparation and assistance.

\section{Author Contributions}

Conceived and designed the experiments: DPG MGF. Performed the experiments: DPG KF JAF. Analyzed the data: DFG KF. Wrote the paper: DPG KF JAF MGF.

15. Kassab GS, Lin DH, Fung YC (1994) Morphometry of pig coronary venous system. Am J Physiol Heart Circ Physiol 267: H2100-H2113.

16. Kuo L, Chancellor JD (1995) Adenosine potentiates flow-induced dilation of coronary arterioles by activating KATP channels in endothelium. Am J Physiol 269: H541-549.

17. Wacker CM, Hartlep AW, Pfleger S, Schad LR, Ertl G, et al. (2003) Susceptibility-sensitive magnetic resonance imaging detects human myocardium supplied by a stenotic coronary artery without a contrast agent. J Am Coll Cardiol 41: 834-840. doi:10.1016/S0735-1097(02)02931-5.

18. Fieno DS, Shea SM, Li Y, Harris KR, Finn JP, et al. (2004) Myocardial perfusion imaging based on the blood oxygen level-dependent effect using T2prepared steady-state free-precession magnetic resonance imaging. Circulation 110: 1284-1290. doi:10.1161/01.CIR.0000140673.13057.34.

19. Manka R, Paetsch I, Schnackenburg B, Gebker R, Fleck E, et al. (2010) BOLD cardiovascular magnetic resonance at 3.0 tesla in myocardial ischemia. J Cardiovasc Magn Reson 12: 54. doi:10.1186/1532-429X-12-54.

20. Atalay MK, Reeder SB, Zerhouni EA, Forder JR (1995) Blood oxygenation dependence of $\mathrm{T} 1$ and $\mathrm{T} 2$ in the isolated, perfused rabbit heart at 4.7T. Magn Reson Med 34: 623-627.

21. Shea SM, Fieno DS, Schirf BE, Bi X, HuangJ, et al. (2005) T2-Prepared steadystate free precession blood oxygen level-dependent MR imaging of myocardial perfusion in a dog stenosis model. Radiology 236: 503-509. doi:10.1148/ radiol.2362040149.

22. Karamitsos TD, Leccisotti L, Arnold JR, Recio-Mayoral A, Bhamra-Ariza P, et al. (2010) Relationship between regional myocardial oxygenation and perfusion in patients with coronary artery disease: insights from cardiovascular magnetic resonance and positron emission tomography. Circ Cardiovasc Imaging 3: 3240. doi:10.1161/CIRCIMAGING.109.860148.

23. Li D, Dhawale P, Rubin PJ, Haacke EM, Gropler RJ (1996) Myocardial signal response to dipyridamole and dobutamine: Demonstration of the BOLD effect using a double-echo gradient-echo sequence. Magn Reson Med 36: 16-20. doi: $10.1002 / \mathrm{mrm} .1910360105$.

24. Arnold JR, Karamitsos TD, Bhamra-Ariza P, Francis JM, Searle N, et al. (2012) Myocardial oxygenation in coronary artery disease: insights from blood oxygen level-dependent magnetic resonance imaging at 3 Tesla. J Am Coll Cardiol 59: 1954-1964. doi:10.1016/j.jacc.2012.01.055.

25. Broten TP, Romson JL, Fullerton DA, Winkle DMV, Feigl EO (1991) Synergistic action of myocardial oxygen and carbon dioxide in controlling coronary blood flow. Circulation Research 68: 531-542. doi:10.1161/ 01.RES.68.2.531. 
26. Alella A, Williams FL, Bolene-Williams C, Katz LN (1955) Interrelation between cardiac oxygen consumption and coronary blood flow. Am J Physiol 183: 570 582.

27. Hsu YY, Kuan WC, Lim KE, Liu HL (2010) Breathhold-regulated blood oxygenation level-dependent (BOLD) MRI of human brain at 3 tesla. J Magn Reson Imaging 31: 78-84. doi:10.1002/jmri.22015.

28. Kannurpatti SS, Biswal BB, Hudetz AG (2002) Differential fMRI-BOLD signal response to apnea in humans and anesthetized rats. Magn Reson Med 47: 864 870. doi: $10.1002 / \mathrm{mrm} .10131$.

29. Rioja E, Kerr CL, McDonell WN, Dobson H, Konyer NB, et al. (2010) Effects of hypercapnia, hypocapnia, and hyperoxemia on blood oxygenation leveldependent signal intensity determined by use of susceptibility-weighted magnetic resonance imaging in isoflurane-anesthetized dogs. Am J Vet Res 71: 24-32. doi:10.2460/ajvr.71.1.24
30. Gauthier CJ, Hoge RD (2012) Magnetic resonance imaging of resting OEF and $\mathrm{CMRO}(2)$ using a generalized calibration model for hypercapnia and hyperoxia. Neuroimage 60: 1212-1225. doi:10.1016/j.neuroimage.2011.12.056.

31. Rothe CF, Stein PM, MacAnespie CL, Gaddis ML (1985) Vascular capacitance responses to severe systemic hypercapnia and hypoxia in dogs. Am J Physiol 249: H1061-1069.

32. Eliades D, Weiss HR (1986) Effect of hypercapnia on coronary circulation Cardiovasc Res 20: 127-133.

33. Arellano R, Jiang MT, O'Brien W, Hossain I, Boylen P, et al. (1999) Acute graded hypercapnia increases collateral coronary blood flow in a swine model of chronic coronary artery obstruction. Crit Care Med 27: 2729-2734.

34. Koehler RC, McDonald BW, Krasney JA (1980) Influence of $\mathrm{CO}_{2}$ on cardiovascular response to hypoxia in conscious dogs. Am J Physiol 239: H545-H558. 